\title{
Research on Irrigation Water Efficiency of Guizhou Province Based on SFA
}

\author{
Kang ZHANG ${ }^{\text {a,b,1 }}$, Yunduo ZHANG ${ }^{\text {b,c }}$, Jiangli ZHENG ${ }^{\text {a,b }}$ and Zhipeng MA \\ ${ }^{a}$ Key Laboratory of the Pearl River Estuarine Dynamics and Associated Process \\ Regulation Ministry of Water Resources, Guangzhou, Guangdong Prcovince, 510611 \\ China \\ ${ }^{\mathrm{b}}$ The Pearl River Hydraulic Research Institute, Guangzhou, Guangdong Prcovince, \\ 510611 China \\ ${ }^{c}$ College of Hydrology and Water Resources, Hohai University, Nanjing, Jiangsu \\ Province, 210098 China
}

\begin{abstract}
The measurement of farmland irrigation water efficiency is an important part of the evaluation of agricultural water saving. Since the method of econometrics research on the relationship between input and output was introduced to the evaluation of irrigation water efficiency, it has provided a new perspective for evaluating irrigation water efficiency. This study takes Guizhou in southwest China as an example, using the SFA method to calculate the technical efficiency of food production and irrigation water from 2011 to 2018, and compares the technical efficiency of irrigation water with the measured irrigation water effective utilization coefficient analysis. The analysis shows that: (1) Guizhou's multi-year average irrigation water technical efficiency value is 0.730 , and the difference between cities is large. $20.8 \%$ of the urban irrigation water technical efficiency is lower than the average level, and there is a large water saving potential; (2) The correlation coefficient between the irrigation water technical efficiency calculated by the SFA method and the measured irrigation water effective utilization coefficient is 0.804 , which is highly positively correlated, and the simulation calculation validity is $70.6 \%$; (3) The SFA method can provide an effective reference for the study of the change trend of the effective utilization coefficient of farmland irrigation water in the absence of measured data.
\end{abstract}

Keywords. Water use efficiency; SFA; Guizhou Province; agricultural water use

\section{Introduction}

At present, China mainly uses the irrigation water effective utilization coefficient (IWEUC) to measure the level of agricultural irrigation water efficiency. And the measurement of IWEUC generally uses the head-to-tail analysis method [1], which is obtained by measuring the net water volume and gross water volume of different irrigation areas. In the actual calculation process, IWEUC is often affected by many factors such as the scale of the irrigation area, the type of water source, the type of soil, the seepage prevention of the canal, and the management level of the management

${ }^{1}$ Kang Zhang, Key Laboratory of the Pearl River Estuarine Dynamics and Associated Process Regulation Ministry of Water Resources, Guangzhou, Guangdong Prcovince, 510611 China; E-mail: zk_xa@163.com. 
department [2]. The calculation cycle is long and requires a lot of manpower, material and financial resources, and the accuracy and authenticity of the calculation results are difficult to review. Therefore, it is urgent to explore scientific and convenient methods for measuring irrigation water efficiency.

Econometrics analyzes the gap between actual production conditions and ideal production conditions from the perspective of input and output. Its mathematical expression is the ratio of actual output to the maximum possible output under certain production input conditions. Commonly used calculation methods in econometrics are stochastic frontier production function method (SFA) and data envelopment analysis method (DEA).

The SFA method can not only quantitatively analyze the specific impact of various input indicators on technical efficiency, but also consider the impact of random errors. Wang [3] used SFA and DEA to measure the irrigation water consumption of 31 provinces in China from 1997 to 2006. They concluded that the technical efficiency calculated by the SFA method is lower than the technical efficiency calculated by the DEA method under variable returns to scale. It is pointed out that the reason for the significant difference in the calculation results is that the technical efficiency measured by the DEA method is a relative efficiency value, except for the difference in the model mechanism, which is greatly affected by the difference in regional efficiency. Therefore, the SFA method has been widely used in many fields.

Kaneko et al. [4] used the SFA method to measure China's agricultural water efficiency from 1999 to 2002; Lei [5] improved Battese's [6] model to build a stochastic frontier analysis model and calculated the Xuzhou city from 2000 to 2007 Technical efficiency of agricultural water use; Wang [7] calculated the production technical efficiency and irrigation water efficiency of Shijin Irrigation District in 1996, 2003 and 2004 by using the transcending logarithmic stochastic frontier production function. In summary, the current research on the measurement of agricultural water use efficiency using the SFA method is mainly carried out at the level of technical efficiency. There are still relatively few studies on the comparison and verification analysis of technical efficiency and actual water use efficiency, especially under complex terrain and landform conditions, where the sample is limited and the sample point is limited. It is difficult to guarantee typicality and representativeness. Therefore, this study chooses Guizhou Province as an example, based on the city-level panel data, the SFA method is used to calculate the technical efficiency of agricultural irrigation water in Guizhou Province from 2011 to 2018, and compared with the measured effective utilization coefficient of irrigation water to analyze the SFA method in Guizhou agricultural irrigation. The applicability and rationality of the field provide support for scientific and accurate assessment of the efficiency of irrigation water use in Guizhou.

\section{Study Area}

Guizhou is located in the eastern part of the Yunnan-Guizhou Plateau in the hinterland of southwestern China. It governs 9 prefecture-level administrative regions with a total area of $176,200 \mathrm{~km}^{2}$, of which $92.5 \%$ are mountains and hills. Guizhou has a subtropical monsoon climate with developed karst topography and landforms, accounting for $61.9 \%$ of the province's total land area. Its water storage conditions are poor, resulting in low water supply guarantee rate, low water resource development and 
utilization, poor runoff regulation and water supply. The problem of low guarantee rate is particularly prominent [8]. Agricultural irrigation water is the largest water user in Guizhou. In 2018, agricultural irrigation water accounted for $54.3 \%$ of the total water consumption. However, due to the complex terrain of Guizhou, the irrigation areas are mostly in mountainous areas, the irrigation water delivery system is long and complex, and the production methods are relatively backward. The traditional direct irrigation, coupled with the old irrigation project, makes the province's agricultural irrigation water efficiency still lower than the national average.

\section{Data and Method}

\subsection{Data}

This study selects panel data from 9 prefecture-level cities in Guizhou Province from 2011 to 2018. The data comes from the "Guizhou Provincial Statistical Yearbook", "Guizhou Provincial Water Resources Bulletin", and the "Statistical Yearbook" and "Water Resources" of 9 prefecture-level cities. In the Bulletin, the data missing rate is about $1 \%$, and linear interpolation is used to interpolate and extend the missing and missed data. Through the screening of relevant agricultural irrigation indicators, the grain yield is selected as the output indicator of the model, and the agricultural labor force, total power of agricultural machinery, fertilizer application, grain sown area and irrigation water consumption are the input indicators. The calculation methods and data sources of each index are shown in table 1.

Table 1. Calculation method and data source of irrigation water technical efficiency index.

\begin{tabular}{|c|c|c|c|c|c|}
\hline $\begin{array}{l}\text { Indicator } \\
\text { type }\end{array}$ & Index & $\begin{array}{l}\text { Calculation } \\
\text { method }\end{array}$ & Dimension & Date sources & Sequence \\
\hline \multirow[t]{3}{*}{$\begin{array}{l}\text { Output } \\
\text { indicators }\end{array}$} & Food production $/ \mathrm{Y}$ & / & $10^{4} \mathrm{t}$ & Statistical Yearbook & 2011 2018 \\
\hline & Labor force $/ \mathrm{L}$ & l & $10^{4}$ people & Statistical Yearbook & к 2011 2018 \\
\hline & Agricultural machinery power /K & l & $10^{8} \mathrm{~W}$ & Statistical Yearbook & 2011 2018 \\
\hline \multirow[t]{4}{*}{$\begin{array}{l}\text { Iutput } \\
\text { indicators }\end{array}$} & Pure fertilizer use $/ \mathrm{H}$ & / & $10^{4} \mathrm{t}$ & Statistical Yearbook & र 2011 2018 \\
\hline & Grain sown area $/ \mathrm{M}$ & / & $10^{3}$ ha & Statistical Yearbook & 2011 2018 \\
\hline & Irrigation water consumption /W & / & $10^{8} \mathrm{~m}^{3}$ & $\begin{array}{l}\text { Water Resources } \\
\text { Bulletin }\end{array}$ & 2011 2018 \\
\hline & Total crop area /MZ & / & $10^{3}$ ha & Statistical Yearbook & र 2011 2018 \\
\hline \multirow{3}{*}{$\begin{array}{l}\text { Other } \\
\text { related } \\
\text { indicators }\end{array}$} & Agricultural output value /NC & / & $10^{8}$ yuan & Statistical Yearbook & र 2011 2018 \\
\hline & $\begin{array}{l}\text { Output Value of Farming, Forestry, } \\
\text { Animal Husbandry, and Fishery /ZC }\end{array}$ & / & $10^{8}$ yuan & Statistical Yearbook & 2011 2018 \\
\hline & Effective irrigation area /YG & l & $6.67 \times 10^{6} \mathrm{~m}^{2}$ & $\begin{array}{l}\text { Water Resources } \\
\text { Bulletin }\end{array}$ & $2011 \sim 2018$ \\
\hline \multirow{2}{*}{$\begin{array}{l}\text { Efficiency } \\
\text { loss index }\end{array}$} & $\begin{array}{l}\text { Total power of labor-forced } \\
\text { agricultural machinery per labor } \\
\text { force /LJNJ }\end{array}$ & $\mathrm{K} / \mathrm{L} * 10$ & $\mathrm{KW} / \mathrm{p}$ & Statistical Yearbook & к 2011 2018 \\
\hline & $\begin{array}{l}\text { Proportion of non-food crops } \\
\text { planted area /FLBL }\end{array}$ & $\begin{array}{l}(1- \\
\mathrm{M} / \mathrm{MZ}) * 100\end{array}$ & $\%$ & Statistical Yearbook & र 2011 2018 \\
\hline
\end{tabular}




\begin{tabular}{|c|c|c|c|}
\hline $\begin{array}{l}\text { Pure amount of uniform fertilizer } \\
\text { use per unit area /MJHF }\end{array}$ & $\begin{array}{l}\mathrm{H} / \mathrm{M} * 10000 \\
/ 15\end{array}$ & $\mathrm{~kg} / 667 \mathrm{~m}^{2}$ & Statistical Yearbook 2011 2018 \\
\hline $\begin{array}{l}\text { average sown area per labor } \\
\text { force/LJMJ }\end{array}$ & $\mathrm{M} / \mathrm{L}$ & $\begin{array}{l}10^{3} \mathrm{ha} / 10^{4} \\
\text { people }\end{array}$ & Statistical Yearbook 2011 2018 \\
\hline The proportion of agriculture /AR & $\mathrm{NC} / \mathrm{ZC}^{*} 100$ & $\%$ & Statistical Yearbook 2011 2018 \\
\hline Irrigated area ratio /IR & $\begin{array}{l}\mathrm{YG} / \mathrm{M} * 100 / \\
1.5\end{array}$ & $\%$ & $\begin{array}{l}\text { Statistical Yearbook } \\
\text { / Water Resources 2011 2018 } \\
\text { Bulletin }\end{array}$ \\
\hline
\end{tabular}

\subsection{Calculation Model of Technical Efficiency of Food Production}

The model of SFA is suggested by Battese \& Coelli (1995) as follows:

$$
\begin{aligned}
& \ln y_{i t}=\beta_{0}+\beta_{1} \ln L_{\mathrm{it}}+\beta_{2} \ln K_{\mathrm{it}}+\beta_{3} \ln H_{\mathrm{it}}+\beta_{4} \ln M_{\mathrm{it}}+\beta_{5} \ln W_{\mathrm{it}}+\beta_{6} T+\beta_{7}\left(\ln L_{\mathrm{it}}\right)^{2}+\beta_{8}\left(\ln K_{\mathrm{it}}\right)^{2}+\beta_{9}(1 \\
& \left.\mathrm{n}_{\mathrm{it}}\right)^{2}+\beta_{10}\left(\ln M_{\mathrm{it}}\right)^{2}+\beta_{11}\left(\ln W_{\mathrm{it}}\right)^{2}+\beta_{12} T^{2}+\beta_{13}(\ln L \times \ln K)_{\mathrm{it}}+\beta_{14}(\ln L \times \times \ln H)_{\mathrm{i}}+\beta_{15}(\ln L \times \ln M \\
& )_{\mathrm{itt}}+\beta_{16}(\ln L \times \ln W)_{\mathrm{it}}+\beta_{17}\left(\ln L_{\mathrm{it}} \times T\right)+\beta_{18}(\ln K \times \ln H)_{\mathrm{it}}+\beta_{19}(\ln K \times \ln M)_{\mathrm{it}}+\beta_{20}(\ln K \times \ln W) \\
& { }_{\mathrm{it}}+\beta_{21}\left(\ln K_{\mathrm{it}} \times T\right)+\beta_{22}(\ln H \times \ln M)_{\mathrm{it}}+\beta_{23}(\ln H \times \ln W)_{\mathrm{it}}+\beta_{24}\left(\ln H_{\mathrm{it}} \times T\right)+\beta_{25}(\ln M \times \ln W)_{\mathrm{it}} \\
& +\beta_{26}\left(\ln M_{\mathrm{it}} \times T\right)+\beta_{27}\left(\ln W_{\mathrm{it}} \times T\right)+\mathrm{v}_{i t}-\mathrm{u}_{\mathrm{it}}
\end{aligned}
$$

In the formula (1), $y$ is the grain output with 10,000 tons; $K$ is the total power of the agricultural machinery (100 million watts); $H$ is the pure fertilizer use (10,000 tons); $M$ is the grain sown area $(10,000 \mathrm{mu}$ or $667 \mathrm{ha}) ; W$ is the amount of irrigation water, $\left(100\right.$ million $\left.\mathrm{m}^{3}\right)$; The time variable is from 1 to 22 years from 1992 to 2013 ; the serial number of the city $\mathrm{i}$ is $1,2, \ldots, 21 ; t$ is the year sequence, and 1 to 8 stands for from 2011 to $2018 ; \beta_{0} \sim \beta_{27}$ is the coefficient of the explanatory variable; $V_{i t}$ are independent and identically distributed random perturbation terms independent of $U_{i t}$, assuming that they follow the standard normal distribution $\mathrm{N}\left(0, \sigma_{U}^{2}\right) ; U_{i t}$ are random variables representing technical efficiency losses assumed to be subject to a non-negative seminormal distribution $\mathrm{N}\left(\mathrm{m}, \sigma_{U}^{2}\right)$, can be expressed as:

$$
\mathrm{u}_{\mathrm{it}}=\delta_{0}+\delta_{1}(\mathrm{LJNJ})_{\mathrm{it}}+\delta_{2}(\mathrm{FLBL})_{\mathrm{it}}+\delta_{3}(\mathrm{MJHF})_{\mathrm{it}}+\delta_{4}(\mathrm{LJNJ})_{\mathrm{it}}+\delta_{5}(\mathrm{AR})_{\mathrm{it}}+\delta_{6}(\mathrm{IR})_{\mathrm{it}}+\varepsilon_{\mathrm{it}}
$$

In the formula (2), LJNJ is the total power of labor-forced agricultural machinery per labor force $(10,000 \mathrm{KW}$ per 10,000 people); FLBL is the ratio of non-food crop cultivation area to the total crop planting area $(\%) ; M J H F$ is the pure amount of uniform fertilizer use per unit area $(\mathrm{kg} / 0.067 \mathrm{ha})$; $L J M J$ is the average sown area per labor force (1,000 hectares per 10,000 people); $A R$ is the proportion of agriculture, (means the proportion of agricultural output accounts for the output value of agriculture, forestry, animal husbandry and fishery, with the unit of $\%$ ); $I R$ is the ratio of grain irrigated area to the grain sown area $(\%) ; \delta_{0} \sim \delta_{6}$ are constants.

According to the study of Kumbhakar and Lovell [9], the technical efficiency of food production can be as formulas (3) and (4):

$$
\begin{aligned}
& \mathrm{TE}_{\mathrm{it}}=\exp \left(-\mathrm{u}_{\mathrm{it}}\right) \\
& \gamma=\frac{\sigma_{\mathrm{u}}^{2}}{\sigma_{\mathrm{v}}^{2}+\sigma_{\mathrm{u}}^{2}}
\end{aligned}
$$


The formula (4) reflects the influence of random error term and efficiency loss term on grain production, $\gamma \in(0,1]$. When $\gamma$ tends to 1 , it means that the gap between actual grain output and maximum grain output is mainly due to technical efficiency Loss is caused; when $\gamma$ tends to 0 , it means that the gap between the actual grain output and the maximum grain output is mainly caused by random errors. The model is tested by the likelihood comparison test method, and the test results are shown in table 2.

Table 2. Hypothesis test analysis table.

\begin{tabular}{|c|c|c|c|c|}
\hline Hypothesis test & $\begin{array}{l}\text { Log likelihood } \\
\text { function value }\end{array}$ & $\begin{array}{l}\text { Statistics } \\
\lambda\end{array}$ & $\begin{array}{l}\text { Critical value } \\
\text { (significance level is } 5 \% \text { ) }\end{array}$ & $\begin{array}{l}\text { Test } \\
\text { result }\end{array}$ \\
\hline $\begin{array}{l}\text { the production function is Cobb-Douglas } \\
\text { function }\left(\mathrm{H}_{0}: \beta_{\mathrm{i}}=0, \mathrm{i}=67, \ldots, 27\right)\end{array}$ & 80.952 & 247.020 & $32.67(\mathrm{n}=21)$ & Reject \\
\hline $\begin{array}{l}\text { there is no change in the technical } \\
\text { efficiency of grain production } \\
\left(\mathrm{H}_{0}: \beta_{\mathrm{i}}=0, \mathrm{i}=6,12,17,21,24,26,27\right)\end{array}$ & 105.068 & 171.568 & $14.07(n=7)$ & Reject \\
\hline $\begin{array}{l}\text { grain production meets Hicks neutral } \\
\text { technological progress } \\
\left(\mathrm{H}_{0}: \beta_{\mathrm{i}}=0, \mathrm{i}=17,21,24,26,27\right)\end{array}$ & 106.487 & 158.414 & $11.07(\mathrm{n}=5)$ & Reject \\
\hline $\begin{array}{l}\text { There is no technical inefficiency } \\
\left(\mathrm{H}_{0}: \delta_{\mathrm{i}}=0, \mathrm{i}=0,1,2, \ldots, 6\right)\end{array}$ & 111.789 & 195.031 & $14.07(\mathrm{n}=7)$ & Reject \\
\hline
\end{tabular}

From the test results in table 2, it can be seen that the 4 hypotheses were rejected at the $5 \%$ significance level, indicating that the trans-logarithmic stochastic frontier production function model constructed in this study is reasonable and applicable.

\subsection{Calculating Model of Irrigation Water Technical Efficiency}

The technical efficiency of irrigation water is expressed as the percentage of the minimum irrigation water consumption to the actual irrigation water consumption under the condition that the output and other input indicators are unchanged. It reflects the single input efficiency theory [10]. The technical efficiency model of irrigation water can be described as:

$$
\theta_{\mathrm{e}}=\min \left\{\Psi: \mathrm{f}\left(\mathrm{x}, \Psi_{\mathrm{W}} ; \rho\right) \geq \mathrm{y}\right\}
$$

In the formula (5), $\theta_{\mathrm{e}}$ represents the technical efficiency of irrigation water, $\theta \mathrm{e} \in$ $(0,1] ; \mathrm{x}$ represents other input variables except irrigation water consumption; $\Psi$ represents the ratio of the minimum irrigation water consumption to the actual irrigation water consumption; $\Psi_{\mathrm{W}}$ is the minimum irrigation consumption; $\rho$ is the coefficient of the explanatory variable.

According to the study of Reinhard et al. (1999), the irrigation water efficiency model can be as formula (6) and (7):

$$
\begin{aligned}
& \theta_{\mathrm{e}}=\exp \left[\left(-\xi \pm \sqrt{\xi^{2}-2 \beta_{11} \mathrm{u}_{\mathrm{it}}}\right) / \beta_{11}\right] \\
& \xi=\frac{\partial \ln y_{\mathrm{it}}}{\partial \ln W_{i \mathrm{t}}}=\beta_{5}+2 \beta_{11} \ln W_{i t}+\beta_{16} \ln L_{i t}+\beta_{20} \ln K_{i t}+\beta_{23} \ln H_{i t}+\beta_{25} \ln M_{i t}+ \\
& \beta_{27} \mathrm{~T}
\end{aligned}
$$




\section{Results}

\subsection{Calculation Results of Technical Efficiency of Food Production}

The maximum likelihood estimation method combined with front 4.1 software is used to estimate the parameters of the model. The results are shown in table 3 .

Table 3. Frontier function and efficiency function estimation results

\begin{tabular}{|c|c|c|c|c|c|}
\hline Function & $\begin{array}{l}\text { Explanatory } \\
\text { variables }\end{array}$ & Parameter & $\begin{array}{l}\text { Parameter } \\
\text { value }\end{array}$ & $\begin{array}{l}\text { Standard } \\
\text { deviation }\end{array}$ & t-test value \\
\hline \multirow{28}{*}{$\begin{array}{l}\text { Frontier } \\
\text { production } \\
\text { function }\end{array}$} & $\begin{array}{l}\text { Constant } \\
\text { term }\end{array}$ & $\beta_{0}$ & -9.3708 & 0.9541 & $9.8216^{* * *}$ \\
\hline & $\ln L$ & $\beta_{1}$ & 5.0491 & 0.6930 & $7.2854 * * *$ \\
\hline & $\ln K$ & $\beta_{2}$ & 1.0277 & 0.7409 & $1.3871^{*}$ \\
\hline & $\ln \mathrm{H}$ & $\beta_{3}$ & -3.2553 & 0.6340 & $-5.1342 * * *$ \\
\hline & $\ln M$ & $\beta_{4}$ & 0.2957 & 0.5254 & $5.628 * * *$ \\
\hline & $\ln W$ & $\beta_{5}$ & -0.0352 & 0.4417 & $-7.97 * * *$ \\
\hline & $\mathrm{T}$ & $\beta_{6}$ & -0.1259 & 0.0802 & $-1.5695 *$ \\
\hline & $(\ln L)^{2}$ & $\beta_{7}$ & -0.0950 & 0.2948 & -0.3222 \\
\hline & $(\ln K)^{2}$ & $\beta_{8}$ & 0.4471 & 0.1431 & $3.1251 * * *$ \\
\hline & $(\ln H)^{2}$ & $\beta_{9}$ & -0.2459 & 0.1075 & $-2.2880 * *$ \\
\hline & $(\ln M)^{2}$ & $\beta_{10}$ & 0.4720 & 0.2865 & $1.6476^{*}$ \\
\hline & $(\ln W)^{2}$ & $\beta_{11}$ & 0.0257 & 0.0453 & 0.5676 \\
\hline & $\mathrm{T}^{2}$ & $\beta_{12}$ & 0.0039 & 0.0020 & $1.9152 * *$ \\
\hline & $\ln L \times \ln K$ & $\beta_{13}$ & 1.3699 & 0.4642 & $2.9509^{* * *}$ \\
\hline & $\operatorname{lnL} \times \ln \mathrm{H}$ & $\beta_{14}$ & -0.6696 & 0.4051 & $-1.6528^{*}$ \\
\hline & $\ln L \times \ln M$ & $\beta_{15}$ & -0.8789 & 0.5462 & $-1.6090 *$ \\
\hline & $\ln L \times \ln W$ & $\beta_{16}$ & -0.1071 & 0.1956 & -0.5478 \\
\hline & $\operatorname{lnL} \times \mathrm{T}$ & $\beta_{17}$ & 0.0580 & 0.0374 & $1.5478 *$ \\
\hline & $\ln \mathrm{K} \times \ln \mathrm{H}$ & $\beta_{18}$ & 0.1638 & 0.2842 & 0.5764 \\
\hline & $\ln K \times \ln M$ & $\beta_{19}$ & 0.1556 & 0.3874 & 0.4016 \\
\hline & $\ln \mathrm{K} \times \ln \mathrm{W}$ & $\beta_{20}$ & -0.1945 & 0.1012 & $-1.9222 * *$ \\
\hline & $\operatorname{lnK} \times \mathrm{T}$ & $\beta_{21}$ & -0.0994 & 0.0340 & $-2.9226 * * *$ \\
\hline & $\ln H \times \ln M$ & $\beta_{22}$ & -0.5751 & 0.3406 & $-1.6883^{*}$ \\
\hline & $\ln \mathrm{H} \times \ln \mathrm{W}$ & $\beta_{23}$ & 0.0121 & 0.1104 & 0.1098 \\
\hline & $\ln \mathrm{H} \times \mathrm{T}$ & $\beta_{24}$ & -0.0270 & 0.0253 & -1.0673 \\
\hline & $\ln M \times \ln W$ & $\beta_{25}$ & 0.1645 & 0.1305 & $1.3599^{*}$ \\
\hline & $\ln M \times T$ & $\beta_{26}$ & 0.0082 & 0.0387 & $2.111 * *$ \\
\hline & $\ln W \times T$ & $\beta_{27}$ & 0.0220 & 0.0106 & $2.082 * *$ \\
\hline \multirow{7}{*}{$\begin{array}{l}\text { Efficiency } \\
\text { loss } \\
\text { function }\end{array}$} & $\begin{array}{l}\text { Constant } \\
\text { term }\end{array}$ & $\delta_{0}$ & -0.1696 & 0.4075 & -0.4162 \\
\hline & LJNJ & $\delta_{1}$ & 0.0002 & 0.0001 & $2.2274 * *$ \\
\hline & FLBL & $\delta_{2}$ & 0.0049 & 0.0042 & 1.1714 \\
\hline & MJHF & $\delta_{3}$ & -0.0148 & 0.0067 & $-2.2174 * *$ \\
\hline & LJMJ & $\delta_{4}$ & -0.1909 & 0.1842 & -1.0360 \\
\hline & $\mathrm{AR}$ & $\delta_{5}$ & 0.0005 & 0.0041 & 0.1190 \\
\hline & IR & $\delta_{6}$ & 0.0048 & 0.0030 & $1.5816^{*}$ \\
\hline \multicolumn{2}{|l|}{$\sigma^{2}$} & & 0.0503 & 0.0048 & $10.4420 * * *$ \\
\hline \multicolumn{2}{|c|}{$\Gamma$} & & 0.9988 & 0.0025 & $142.3856^{* * *}$ \\
\hline \multicolumn{2}{|c|}{ Likelihood function value } & & 168.46 & & \\
\hline \multicolumn{2}{|c|}{ Likelihood ratio $\lambda$} & & 66.24 & & \\
\hline \multicolumn{2}{|c|}{ Likelihood function value } & & 0.8777 & & \\
\hline
\end{tabular}

In table 3, in the frontier production function, the four input parameters of agricultural labor force, fertilizer application, grain sown area and irrigation water 
consumption have passed the significance test at the $1 \%$ level, and the parameters of the total power of agricultural machinery are passed the significance test at the $10 \%$ level. It can be seen from the sign of the coefficient that the agricultural labor force, the total power of agricultural machinery, and the sown area of grain are positively correlated with grain production, indicating that these three input indicators have a positive impact on the grain production in Guizhou Province. The negative correlation indicates that the two input indicators have a negative impact on the grain production. In the efficiency loss function, the total power of agricultural machinery per labor and the average fertilizer application per mu passed the significance test at the 5\% level, and the irrigated area ratio passed the significance test at the $10 \%$ level. The sign of the coefficient of the total power of agricultural machinery and the proportion of irrigated area per labor is positive, which is positively correlated with the efficiency loss, indicating that the two input indicators have a negative impact on technical efficiency; the sign of the coefficient of the fertilizer application per mu is negative, which is proportional to the efficiency loss. A negative correlation indicates that the input indicator has a positive impact on technical efficiency. The loss of technical efficiency is the main reason for the gap between the actual grain output and the maximum grain output. From 2011 to 2018, the average technical efficiency of grain production in Guizhou Province was 0.8777 , indicating that under the current technical conditions, keeping production input unchanged, if the loss of technical efficiency is not taken into account, the technical efficiency of grain production can also increase by $12.23 \%$.

\subsection{Calculation Results of Irrigation Water Technical Efficiency}

The statistics of the calculation results of the irrigation water technical efficiency calculation model are shown in table 4. The multi-year average technical efficiency value is 0.730 , which means that the irrigation water consumption can be reduced by $27.0 \%$ while keeping the current grain output and other inputs unchanged. Judging from the distribution of the average irrigation water technical efficiency in eight years, cities with a technical efficiency lower than 0.5 accounted for $6.94 \%$, cities with a technical efficiency between 0.5 and 0.8 accounted for $59.73 \%$, and cities with a technical efficiency greater than 0.8 accounted for $33.33 \%$. The overall irrigation technical efficiency of water use is at the mid-to-upper level, but the differences between cities are large, and $20.8 \%$ of the urban irrigation water technical efficiency values are lower than the multi-year average, which still needs to be further improved.

Table 4. Distribution of technical efficiency of irrigation water from 2011 to 2018.

\begin{tabular}{lllllllllll}
\hline$\theta_{\mathrm{e}}$ & 2011 & 2012 & 2013 & 2014 & 2015 & 2016 & 2017 & 2018 & Average $\begin{array}{l}\text { Cumulative } \\
\text { percentage } / \%\end{array}$ \\
\hline$<0.5$ & 5 & 0 & 0 & 0 & 0 & 0 & 0 & 0 & 0.625 & 6.94 \\
{$[0.5,0.8]$} & 4 & 8 & 8 & 5 & 5 & 4 & 5 & 4 & 5.375 & 66.67 \\
$>0.8$ & 0 & 1 & 1 & 4 & 4 & 5 & 4 & 5 & 3.000 & 100.00 \\
$\max$ & 0.597 & 0.872 & 0.945 & 0.994 & 0.919 & 0.998 & 0.999 & 0.997 & 0.915 & \\
min & 0.410 & 0.591 & 0.604 & 0.665 & 0.620 & 0.642 & 0.541 & 0.542 & 0.577 & \\
mean & 0.489 & 0.685 & 0.682 & 0.793 & 0.782 & 0.828 & 0.771 & 0.812 & 0.730 & \\
\hline
\end{tabular}

In order to verify the rationality of the change trend of IWEUC, the technical efficiency of irrigation water used in Guizhou Province from 2011 to 2018 calculated by the SFA method was compared with the actual IWEUC (figure 1). In figure 1, 
IWEUC measured in Guizhou Province varies from 2011 to 2018 in the range of [0.428, 0.472 ], which is small, and the overall efficiency is not high, but it is increasing year by year. the trend of. Comparing the trend lines of the two, the slope of the trend line of irrigation water technical efficiency is 0.0372 , which is greater than the slope of the measured IWEUC, but the trend of the two is basically the same, showing a positive correlation. The correlation coefficient of the two curves is $\mathrm{R}=0.804$, and $\mathrm{T}=4.439>\mathrm{t}_{0.05}=2.365$ is obtained by the $\mathrm{t}$-test analysis. There is a good correlation between them; the root mean square error $\mathrm{RMSE}=0.294$, which means that the calculated value of irrigation technical efficiency differs from IWEUC by $29.4 \%$. The validity of the simulation calculation result is $70.6 \%$, and the fitting effect is average.

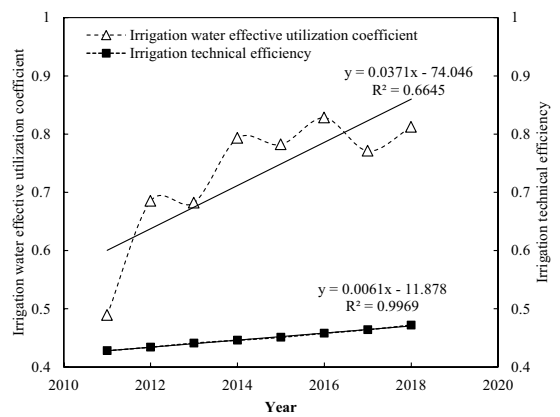

Figture 1. Changes of irrigation water efficiency and IWEUC in Guizhou Province.

\section{Discussion}

The technical efficiency of irrigation water calculated by the SFA method is highly correlated with the measured IWEUC, but there is still a certain deviation, indicating that there is still room for adjustment in the structure of the beyond log stochastic frontier production function model. In the measurement of the IWEUC, many factors such as the scale of the irrigation area, soil texture, water source type, and canal seepage control are considered and needing to be measured. The study area simulated by the SFA method is the whole Guizhou Province, and irrigation area is not divided. Thus the study area is relatively large, and the factors considered are only the 6 input indicators. In addition, the comparison results also provide a direction for improving the research method. When using the SFA method to simulate the technical efficiency of irrigation water, if more relevant indicators are considered and the indicators are more sensitive, then the research scope will be further reduced. The calculation may achieve higher validity and the simulation effect is better. The high consistency between the technical efficiency of irrigation water and the change trend of the measured IWEUC can be used to carry out the change of the IWEUC in the absence of actual measurement data.

\section{Conclusions}

This paper selects panel data of 9 cities in Guizhou Province from 2011 to 2018, and uses the SFA method combined with the maximum likelihood estimation method and 
the Front 4.1 software to perform irrigation. By estimating the model parameters and calculating the technical efficiency of food production, the technical efficiency of irrigation water is then calculated, and compared with the measured effective utilization coefficient of irrigation water, the following conclusions can be drawn:

(1) The average technical efficiency of irrigation water in Guizhou in the past 8 years is 0.730 , which is lower than that of grain production technology and has a certain potential for water saving. The overall technical efficiency of irrigation water is in the upper-middle level, but the differences between cities are large, and $20.8 \%$ urban irrigation water technical efficiency is less than the multi-year average, which still needs to be further improved;

(2) The simulation calculation result of irrigation water technical efficiency is general. The validity of the simulation calculation is $70.6 \%$, and the correlation coefficient $\mathrm{R}=0.804$. The influencing factors of IWEUC and the sensitivity of model input indicators adjust the model structure and refine the study area to calculate to achieve better simulation results.

(3) In the absence measured data area, the SFA method is used to calculate the change trend of irrigation water technical efficiency, which can provide reference for the IWEUC.

\section{Acknowledgments}

This work was supported by Guizhou Province Water Resource Science and Technology Fund Project (KT201904) and Key R\&D Program of Guangxi Zhuang Autonomous Region (No.902229136010). The author thanks Fan Qunfang for her help in software use and preliminary research.

\section{References}

[1] Gao F, Zhao JC, Xu JZ, et al. Study on measuring method of utilizaion coefficient of irrigation water. Journal of Irrigation and Drainage. 2004 Feb; 23(1): 14-20. (in Chinese)

[2] Zhang ZC and Song ZY. Analysis on influencing factors of effective utilization coefficient of farmland irrigation water. Hunan Hydropower. 2020 Oct; 65(5): 68-69. (in Chinese)

[3] Wang XY. Comparative study on irrigation water efficiency of chinese provinces based on DEA and SFA methods. Statistics \& Decision. 2010 Aug; 26(8): 44-47. (in Chinese)

[4] Kaneko S, Tanaka K and Toyota T. Water efficiency of agricultural production in China: regional comparison from 1999 to 2002. International Journal of Agricultural Resources Governance and Ecology. 2004 Feb; 3: 231-251.

[5] Lei GR, Hu ZhY and Han G. Technical efficiency and water saving potential in agriculture water based on SFA. Journal of Economics of Water Resources. 2010 Jan; 28: 55-58+77-78. (in Chinese)

[6] Battese GE and Coelli TJ. A model for technical inefficiency effects in a stochastic frontier production function for panel data. Empirical Economics. 1995 Jun; 20: 325-332.

[7] Wang AJ and Li Zh. Analysis of irrigation water use efficiency and influencing factors. Chinese Rural Economy. 2005 Jul; 7: 11-18. (in Chinese)

[8] Cai ChJ, Wang YP, Wang Q, et al. Analysis and research on current situation of irrigation water utilization coefficient in Guizhou Province. Water Saving Irrigation. 2010; 35: 81-83.

[9] Kumbhakar SC, Lovell CAK. Stochastic frontier analysis. Cambridge: Cambridge University Press; 2000. p.343.

[10] Reinhard S, Lovell CAK and Thijssen GJ. Econometric estimation of technical and environmental efficiency: An application to dutch farms. American Journal of Agricultural Economics. 1999 Feb; 81: 44-60. 